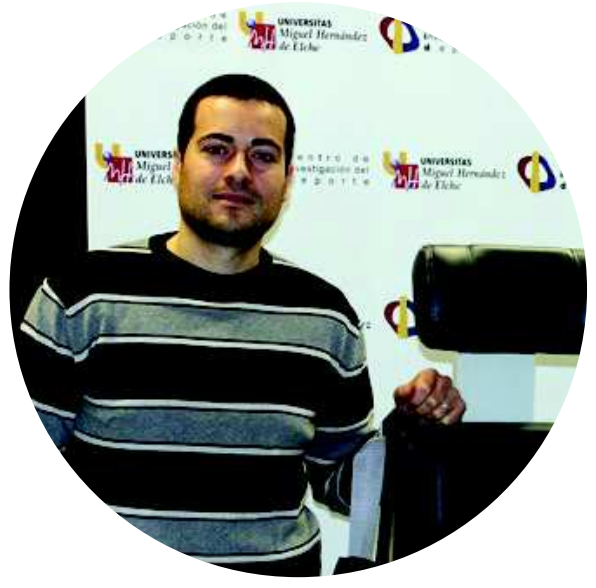

- MCarmen Alabort

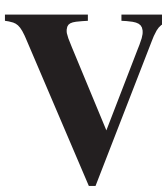

icente Javier Beltrán, profesor del Grado en Ciencias de la Actividad Física y del Deporte de la Universidad Miguel Hernández (UMH) de Elche, ha dedicado su carrera a la investigación para la promoción de la actividad física saludable, sobre todo en adolescentes. Esta carrera le ha llevado a conseguir el Accésit al Mejor Joven Investigador menor de 35 años en el campo social de las Ciencias del Deporte, uno de los galardones del Premio Nacional Jóvenes Investigadores 2014 convocado en el marco del VIII Congreso Internacional de la Asociación Española de Ciencias del Deporte. El doctor Beltrán, que forma parte del Grupo de Investigación en Biomecánica para la Salud y el Rendimiento Deportivo y colabora en el de Comportamiento Motor del Centro de Investigación del Deporte (CID) de la UMH, asegura que deberían existir más programas de promoción de la actividad física saludable "impulsados directamente desde la Administración Pública”.

\section{"En las escuelas, la educación y la salud deben primar por encima del rendimiento deportivo"}

\author{
Vicente Javier Beltrán \\ Premio Nacional 2014 al Mejor Joven Investigador en \\ el Área Psicosocial de las Ciencias del Deporte
}

Accésit a la investigación en Ciencias del Deporte en el campo social, ¿qué líneas de investigación abarca este campo?

Yo trabajo principalmente en la promoción de la actividad física en adolescentes para prevenir las enfermedades derivadas del sedentarismo. Dentro de esa línea general, realizamos tres tipos de estudios. El primero trata de medir los niveles de sedentarismo de los adolescentes, para saber en qué medida existe o no un problema de salud pública por este motivo. Luego hacemos otros estudios para analizar los factores que influyen en la participación, nos interesa saber por qué la gente realiza o no ejercicio físico, para mejorar la promoción de la actividad física en la sociedad. Y los últimos estudios se basan en aplicar el conocimiento generado. Tratamos de realizar intervenciones para promocionar la actividad física y la salud, y luego evaluamos para ver qué hemos conseguido y qué podemos mejorar.

\section{¿En qué consisten las intervenciones?} Las realizamos en los colegios y trabajamos en tres frentes. Ayudamos a los profesores a construir las unidades didácticas, sobre todo en relación al bloque de contenidos de condición física y salud. Realizamos programas de actividad física extracurriculares, en los que tratamos de hacer diferentes juegos y actividades para que el ejercicio sea sano y saludable. Hay un porcentaje de resistencia aeróbica, de trabajo de fuerza y también de flexibilidad. Trabajamos la condición física siempre relacionada con la salud. También hacemos reuniones con los padres. Esta actividad es muy importante dentro de las intervenciones, pues el papel de ellos es fundamental para que esos hábitos se consoliden.

$¿$ Existen muchos factores que puedan influir en que un adolescente desarrolle una identidad activa o sedentaria?

Hay factores sociodemográficos. Bastantes estudios demuestran que las personas con estatus socioeconómico bajo suelen ser más sedentarias que las de estatus alto. Se entiende que esa población tiene menos recursos y acceso a la información para darle importancia a las cosas que tienen que ver con la salud. Con la dieta pasa algo parecido. Luego hay factores de tipo ambiental, el clima influye bastante, aquí tenemos una ventaja con eso. La seguridad ciudadana también es un factor, a más seguridad en los barrios y en las instalaciones públicas más práctica de actividad física, lógicamente. Hay factores de muchos tipos, pero en general todo el proceso de industrialización influye en contra, pues reduce las necesidades de actividad física en la vida diaria. Hay gente que puede vivir moviéndose poquísimo y esto antes no sucedía, porque la sociedad no te ofrecía esa posibilidad. Si una persona ya de por sí es sedentaria, y además trabaja sentado en una oficina, coge el coche, el ascensor... Al final, ¿cuál es el volumen de actividad física que realiza? Esto es un riesgo. 


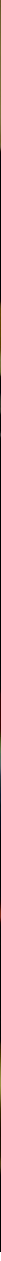

\section{$Y$ ¿respecto a los factores sociales?}

Un factor que influye mucho es la figura del profesor de Educación Física, la de los padres y compañeros. Algo que nos ha llamado mucho la atención, y de hecho forma parte de los artículos que envié al premio, es cómo las experiencias negativas en Educación Física te pueden marcar de por vida. En un estudio con adolescentes de 18 años, había una pregunta clave: ¿qué es lo más positivo y lo más negativo que recuerdas de tus experiencias deportivas? Los adolescentes sedentarios confluían en un patrón común: experiencias positivas no recordaban casi, pero sí las negativas con mucha claridad y muy concretas. Típicas situaciones de insultos por la forma corporal o por la falta de habilidad.

Eso perjudica la autoestima y es lógico que la persona acabe eludiendo esas situaciones, dedicándose a otro tipo de ocio y consolidando hábitos sedentarios. Es un problema que hay que evitar

En ese artículo hablaba de esas experiencias como un reflejo de la cultura de la performatividad, que acaba promoviendo la inactividad.

Sí, es el marco teórico que utilizamos para explicar a nivel sociológico ese fenómeno. Esta cultura está relacionada con las estructuras socioeconómicas y la manera de entender la sociedad de los países desarrollados occidentales. En términos económicos, sabemos que la iniciativa principal es la neoliberal, y esto tiene mucho que ver con la valoración del rendimiento, el ganar a costa de todo, la competitividad, el individualismo... Esto está muy presente en el mundo de la economía y las finanzas, lo que tratamos de explicar es cómo toda esa cultura de la performatividad y del rendimiento se va filtrando en otros contextos. Por ejemplo, en el mundo del deporte de élite, ¿cuándo se da? Cuando yo me dopo para ganar, cuando soy el mejor pero el día que pierdo soy el demonio... Eso pasa mucho, lo vemos constantemente en televisión. $Y$ esa cultura del rendimiento es peligrosa si la tomamos a rajatabla.

\section{¿Cómo afecta esa cultura en un contexto} escolar?

Esa cultura, que es negativa en esa parte, se filtra en la escuela y encontramos los mismos problemas. Imagina un partidillo de chavales de 8 o 13 años donde el que no juega muy bien no sale del banquillo. No están jugando la Champions, sin embargo el chaval menos habilidoso no juega porque aumenta la probabilidad de que su equipo pierda, aunque haya ido a todos los entrenamientos. Es un claro ejemplo de cómo el rendimiento importa más que valorar el esfuerzo del chaval. La escuela es una institución que, por ley, debe beneficiar a todos los alumnos. Este tipo de cosas van en contra de la promoción de la actividad física en un contexto donde debe primar la educación y la salud por encima del rendimiento deportivo.
¿Cree que deberían existir más programas de promoción de la actividad física impulsados desde las instituciones públicas? Una medida muy directa y fácil de organizar sería el aumento de las horas de Educación Física en primaria y secundaria. Luego, desde la Administración Pública, junto al deporte escolar que ya existe, debería impulsarse una oferta de programas de actividad física, relacionados con esa filosofía de trabajo asociada al fomento de hábitos saludables y valores educativos. Algo que también tendría que impulsarse desde la política es la aproximación del mundo de los hospitales y centros sanitarios a las Ciencias del Deporte y sus profesionales. Por ejemplo, el CID colabora con el Hospital del Vinalopó para el fomento de hábitos saludables. Hay un grupo de médicos de atención primaria que trata a niños y adolescentes $y$ un programa de ejercicio que dirigimos desde el CID. Este ejemplo no debe ser aislado, tiene que ser algo impulsado directamente desde la Administración Pública. 